\title{
Development of Polymorphic Microsatellite Loci for Potato Wart from Next-Generation Sequence Data
}

\author{
Marie-Claude Gagnon, Theo A. J. van der Lee, Peter J. M. Bonants, Donna S. Smith, \\ Xiang Li, C. André Lévesque, and Guillaume J. Bilodeau
}

First and seventh authors: Canadian Food Inspection Agency, 3851 Fallowfield Road, Ottawa, ON K2H 8P9, Canada; second and third authors: Wageningen University and Research Center, Droevendaalsesteeg 1, 6708 PB Wageningen, The Netherlands; fourth and fifth authors: Canadian Food Inspection Agency, 93 Mount Edward Road, Charlottetown, PEI C1A 5T1, Canada; and sixth author: Agriculture and AgriFood Canada, 960 Carling Ave, Ottawa, ON K1A 0C6, Canada. Accepted for publication 24 January 2016.

\begin{abstract}
Gagnon, M.-C., van der Lee, T. A. J., Bonants, P. J. M., Smith, D. S., Li, X., Lévesque, C. A., and Bilodeau, G. J. 2016. Development of polymorphic microsatellite loci for potato wart from next-generation sequence data. Phytopathology 106:636-644.

Synchytrium endobioticum is the fungal agent causing potato wart disease. Because of its severity and persistence, quarantine measures are enforced worldwide to avoid the spread of this disease. Molecular markers exist for species-specific detection of this pathogen, yet markers to study the intraspecific genetic diversity of $S$. endobioticum were not available. Whole-genome sequence data from Dutch pathotype 1 isolate MB42 of S. endobioticum were mined for perfect microsatellite motifs. Of the 62 selected microsatellites, 21

could be amplified successfully and displayed moderate levels of polymorphism in $22 S$. endobioticum isolates from different countries. Nineteen multilocus genotypes were observed, with only three isolates from Canada displaying identical profiles. The majority of isolates from Canada clustered genetically. In contrast, most isolates collected in Europe show no genetic clustering associated with their geographic origin. S. endobioticum isolates with the same pathotype displayed highly variable genotypes and none of the microsatellite markers correlated with a specific pathotype. The markers developed in this study can be used to assess intraspecific genetic diversity of S. endobioticum and allow track and trace of genotypes that will generate a better understanding of the migration and spread of this important fungal pathogen and support management of this disease.
\end{abstract}

Synchytrium endobioticum (Schilb.) Percival is a chytrid fungus which causes potato wart disease that has been reported in several countries of the world, including most of Europe and parts of Canada (Obidiegwu et al. 2014; Smith et al. 1997). This obligate parasite is able to infect certain members of the order Solanaceae, with potato (Solanum tuberosum) being the main cultivated host. Potato tubers infected with $S$. endobioticum develop tumor-like galls or warts that render them unmarketable. Warts consist of hypertrophied host cells, each containing a single summer sporangia, which will eventually release infectious zoospores that infect surrounding host cells (Alexopoulos et al. 1996; Hampson 1993). Under certain stress conditions such as water shortage, zoospores fuse to form a zygote that has a thick-walled envelope called the resting or winter sporangium (Alexopoulos et al. 1996; Hampson 1993; Hampson et al. 1994). These resting sporangia are very resistant and can remain viable in the soil for up to 30 years (Hampson 1993; Smith et al. 1997). Because of its severity and persistence, and also because there are no approved chemical treatments against potato wart, quarantine measures and legislation have been applied throughout the world to prevent and control the spread of this disease (Obidiegwu et al. 2014; Smith et al. 1997). This plant pathogen is on the federal select agent program list in United States.

The first detection of potato wart in North America occurred in 1909 on the island of Newfoundland, before this province joined the Canadian Confederation (Hampson 1993). As elsewhere in the world, the spread of the disease in Newfoundland is thought to have happened mainly through human transportation, such as movement

Corresponding author: G. J. Bilodeau;

E-mail address: Guillaume.Bilodeau@canada.ca

http://dx.doi.org/10.1094/PHYTO-12-15-0317-R

(C) 2016 The American Phytopathological Society of contaminated manure or infested soil or exchange of infected seed potato among growers (Hampson 1993). As early as 1912, phytosanitary measures were applied to prevent the spread of the pathogen to Canada (Hampson 1993). Measures such as a system of car washes on ferries, control of the movement of equipment and soil, and cleaning and disinfecting of machinery are still applied in Newfoundland today.

Potato wart was detected for the first time in a field of Prince Edward Island (PEI) in 2000 (De Boer 2001). Other detections of the pathogen have occurred since and they can usually be linked to the initial detection in 2000. The most recent detection occurred in a different location on the island in 2014 and the source of the infestation or possible linkages to previous detections could not be confirmed without a doubt. To better trace back these detections and to manage the disease on PEI or in other countries, characterization of Synchytrium endobioticum diversity is essential. A system to characterize genetic diversity in S. endobioticum would also be very useful in the context of the select agent program in United States, where the source of an introduction would need to be tracked down.

Few markers are available to characterize $S$. endobioticum diversity. One tool that is available is pathotype determination by inoculation tests performed on sets of differential potato cultivars (Baayen et al. 2006; Hampson 1993; Langerfeld and Stachewicz 1994; Langerfeld et al. 1994; Obidiegwu et al. 2014). S. endobioticum comprises several pathotypes, all displaying varying pathogenicity on different potato cultivars. Although pathotyping is useful for authorities and growers because they can use this information to plant resistant potato cultivars on land infested or presenting a risk of being infested with $S$. endobioticum as part of a pest suppression strategy, the lack of standardization and harmonization of this information hampers a good comparison of described pathotypes among countries (Baayen et al. 2006). In addition, pathotype determination is time consuming and is not necessarily informative 
of the genetic diversity present in S. endobioticum isolates within or among countries.

Other molecular markers available are polymerase chain reaction (PCR) and real-time PCR assays, as well as microarrays used for the detection of S. endobioticum in environmental samples (Abdullahi et al. 2005; Niepold and Stachewicz 2004; Smith et al. 2014; van den Boogert et al. 2005; van Gent-Pelzer et al. 2010). These molecular markers can be used as diagnostic tools for the sensitive and specific detection of potato wart, notably in soil samples. These assays are based either on the 18S (Abdullahi et al. 2005) or the internal transcribed spacer region of the ribosomal DNA (rDNA) cistron (Niepold and Stachewicz 2004; Smith et al. 2014; van den Boogert et al. 2005; van Gent-Pelzer et al. 2010). However, despite the fact that these regions display good interspecific variation, no intraspecific variation has been observed at any nuclear rDNA loci in $S$. endobioticum, including the intergenic nontranscribed spacer (IGS) (Smith et al. 2014).

Polymorphic molecular markers, such as microsatellite loci, would be useful to characterize the intraspecific diversity of S. endobioticum isolates. Microsatellite markers, also called simple sequence repeats or short tandem repeats, are sequences of 2 to $6 \mathrm{bp}$ repeated in tandem. This type of codominant marker is generally hypervariable (Tautz 1989) due to its high mutation rate (Ellegren 2000) and has a wide distribution throughout prokaryotic and eukaryotic genomes ( $\mathrm{Li}$ et al. 2002), including fungi (Karaoglu et al. 2005). These characteristics make microsatellites the markers of choice for the analysis of intraspecific diversity, strain typing, and population genetics in many species. In the case of $S$. endobioticum, the development of microsatellite markers might help to get a better understanding of the migration and spread of S. endobioticum around the globe, and help authorities to react more effectively in case of a new detection by providing strain identification for tracing back the origin of the disease.

The objectives of this study were to (i) develop polymorphic microsatellite markers to characterize the genetic diversity of $S$. endobioticum isolates in Canada and (ii) genotype a panel of S. endobioticum isolates from different countries with these new markers. To achieve these objectives, a whole-genome sequence was screened for perfect microsatellite motifs to design primers and test for new microsatellite assays in S. endobioticum.

\section{MATERIALS AND METHODS}

Whole-genome sequencing and de novo assembly. A draft of the genome of isolate MB42 originating from The Netherlands with pathotype 1 was sequenced using a combination of 454 GS-FLX Titanium sequencing and Illumina HiSeq sequencing. S. endobioticum is an obligate biotroph and the sequences could be contaminated with sequences originating from its host potato; therefore, sequences of potato were removed. This first-draft genome contained 2,310 contigs comprising 51,138,234 bp (T. A. J. van der Lee, unpublished data).

Microsatellite isolation, primer design, and optimization. The software MsatCommander version 1.0.8 beta (Faircloth 2008) was used to identify perfect microsatellite motifs varying from 2 to $6 \mathrm{bp}$ repeats in a draft genome assembly of the MB42 genome. PRIMER3 (Rozen and Skaletsky 2000), as implemented in MsatCommander version 1.0.8 beta, was used for primer design for all loci displaying possible primer annealing sites. Primer selection criteria included an optimum melting temperature $=60^{\circ} \mathrm{C}$, optimum GC content $=50 \%$, primer lengths of 18 to $23 \mathrm{bp}$, avoidance of secondary structures, and PCR product size of 150 to $450 \mathrm{bp}$.

Microsatellites $(n=62)$ with the largest number of repeats in the 2- to 6-bp categories were selected and tested on three isolates comprising different pathotypes (NL-02, DE-01, and UK-01) (Table 1) for amplification success. The primer pairs that amplified consistently and that produced amplicons in all isolates were then used to screen for polymorphism on an ABI 3130 xl Genetic Analyzer using a larger panel of isolates coming from different countries and comprising different pathotypes (Table 1).

Universal fluorescent labeling (Schuelke 2000; Shimizu et al. 2002) was used to avoid the cost of genotyping with individual fluorescently labeled primers. This method comprises a universal fluorescent M13 primer (FAM or HEX labeled) and the addition of an M13reverse tag (5'-CAGGAAACAGCTATGACC- $\left.3^{\prime}\right)$ complementary to the universal fluorescent primer at the $5^{\prime}$ end of the sequence-specific forward primer (Schuelke 2000; Shimizu et al. 2002).

DNA extractions and genotyping. The DNA used to screen the microsatellite assays for polymorphism was extracted by different laboratories (Table 1) from either fresh or frozen wart tissue using a Qiagen DNeasy Plant kit (Qiagen Inc., Toronto, ON, Canada) or from S. endobioticum winter sporangia using the extraction method described below. Whole-genome amplification was performed on most of the DNA samples to increase the available amount of genomic DNA using the REPLI-g Mini Kit protocol (Qiagen Inc.).

To extract DNA from winter sporangia, a winter spore suspension containing approximately $100 \mathrm{mg}$ of spores was pipetted into a 2-ml screw-cap tube. The spores were pelleted at $10,000 \times g$ for $1 \mathrm{~min}$ and the supernatant was removed and discarded. To the pellet, $0.5 \mathrm{ml}$ of lysis buffer KF (Promega Corp., Madison, WI), $2 \mu \mathrm{l}$ of RNAse A $(110 \mathrm{mg} / \mathrm{ml}$; Qiagen Inc.), $25 \mu \mathrm{l}$ of antifoam B (Sigma-Aldrich Canada Inc., Oakville, ON, Canada), and $1.5 \mathrm{~g}$ of $2.0-\mathrm{mm}$ zirconia beads (BioSpec Products Inc., Bartlesville, OK) were added. The mixture was processed in a Beadbeater 96 (BioSpec Products Inc.) for 1 min at room temperature. After centrifugation for $1 \mathrm{~min}$ at $10,000 \times g$, the supernatant was transferred into a clean tube. The pellet was resuspended with another $0.5 \mathrm{ml}$ of lysis buffer $\mathrm{KF}$ and recentrifuged. This second supernatant was added to the first supernatant. Then, $100 \mu \mathrm{l}$ of $10 \mathrm{M}$ ammonium acetate was added to the combined supernatant fraction, mixed, and incubated at $4{ }^{\circ} \mathrm{C}$ for 15 to $60 \mathrm{~min}$.

The DNA was recovered from the lysate using the Kingfisher ml magnetic particle processor (Thermo Fisher Scientific Inc., Waltham, MA). During the $4^{\circ} \mathrm{C}$ incubation, a Kingfisher $\mathrm{ml}$ sample strip was preloaded with components required as follows: well 1,0.2 ml of paramagnetic beads (Promega Corp.); well 2, $1 \mathrm{ml}$ of salt wash (Promega Corp.); wells 3 and 4, $1 \mathrm{ml}$ of alcohol wash (Promega Corp.); and well 5, $125 \mu \mathrm{l}$ of sterile, nuclease-free water (Promega Corp.).

After incubation at $4^{\circ} \mathrm{C}$, the spore lysate was centrifuged at $10,000 \times g$ for $1 \mathrm{~min}$, and the supernatant was added to the first well of a Kingfisher sample strip. The samples were placed in the Kingfisher magnetic particle processor, and DNA was extracted and eluted into well 5 using the PromegaGenomic program. The contents of well 5 were transferred to a sterile 1.5 -ml tube and stored at $-20^{\circ} \mathrm{C}$. DNA concentrations were measured with Qubit assays (Life Technologies Inc., Grand Island, NY).

Amplification reactions were carried out in a volume of $25 \mu \mathrm{l}$ with the following final concentrations: $1 \times$ buffer; $0.2 \mathrm{mM} \mathrm{dNTP}$; $0.1 \mu \mathrm{M}$ each M13reverse-tag, tag-forward, and reverse primers; $2 \mathrm{mM} \mathrm{MgCl} 2 ; 0.04 \mathrm{U}$ of Platinum Taq DNA polymerase (Life Technologies Inc.); and approximately $2 \mathrm{ng}$ of template DNA. PCR conditions were $4 \mathrm{~min}$ at $95^{\circ} \mathrm{C} ; 5$ cycles of $20 \mathrm{~s}$ at $95^{\circ} \mathrm{C}, 30 \mathrm{~s}$ at $60^{\circ} \mathrm{C}$, and $60 \mathrm{~s}$ at $72^{\circ} \mathrm{C} ; 20$ cycles of touchdown of $20 \mathrm{~s}$ at $95^{\circ} \mathrm{C}, 30 \mathrm{~s}$ at 60 to $50^{\circ} \mathrm{C}$ (dropping $0.5^{\circ} \mathrm{C}$ per cycle), and $60 \mathrm{~s}$ at $72^{\circ} \mathrm{C} ; 10$ cycles of $20 \mathrm{~s}$ at $95^{\circ} \mathrm{C}, 30 \mathrm{~s}$ at $50^{\circ} \mathrm{C}$, and $60 \mathrm{~s}$ at $72^{\circ} \mathrm{C}$; and one final step of $30 \mathrm{~min}$ at $72^{\circ} \mathrm{C}$.

PCR products $(5 \mu \mathrm{l})$ were first run on $1.5 \%$ agarose gels to check for successful amplification and subsequently run on an ABI 3130xl Genetic Analyzer (Life Technologies Inc.) to check for variability in repeat length among isolates. PCR product $(1 \mu \mathrm{l})$ was suspended in $14 \mu \mathrm{l}$ of Hi-Di Formamide (Life Technologies Inc.) and $0.3 \mu \mathrm{l}$ of GeneScan 500 LIZ dye Size Standard (Life Technologies Inc.). Two PCR products with different fluorescent dyes (FAM and HEX) were 
comigrated at a same time. Results were analyzed using GeneMapper v. 5 (Life Technologies Inc.).

Genetic analyses. Because $S$. endobioticum can undergo both sexual and asexual phases, analyzing methods suitable to address clonality in populations were chosen, as reviewed by Arnaud-Haond et al. (2007). For all polymorphic loci providing clear electropherograms, we estimated the overall number of alleles, Simpson's index of diversity (1-D) (Simpson 1949), evenness, and expected heterozygosity (Nei 1978). We also calculated a genotype accumulation curve with 1,000 resamplings without replacement to assess whether the loci developed in this study were powerful enough to discriminate between the different $S$. endobioticum isolates. For all isolates genotyped, we estimated the observed number of multilocus genotypes as well as expected heterozygosity (Nei 1978). All analyses were conducted using RStudio (version 0.98.501 and R version 3.0.2; R Core Team, Vienna) and the package Poppr (Kamvar et al. 2014).

To assess the relationships between isolates, a principal component analysis (PCA) was performed using Bruvo's genetic distance (Bruvo et al. 2004). Neighbor-joining analyses were also performed using Bruvo's (Bruvo et al. 2004) and Cavalli-Sforza and Edwards' (1967) genetic distances with 1,000 bootstraps (Felsenstein 1985). Bruvo's genetic distance takes into account stepwise mutational processes for microsatellites and allows combined analysis of diploids and polyploids (Bruvo et al. 2004). Cavalli-Sforza and Edwards' chord distance does not take into account mutations and is based, rather, on genetic drift (Cavalli-Sforza and Edwards 1967). These analyses were conducted using RStudio and the packages Polysat version 1.3-2 (Clark and Jasieniuk 2011) and Poppr (Kamvar et al. 2014).

Finally, the program Structure version 2.3.4 (Pritchard et al. 2000) was used to determine the number of genetic clusters present in our panel of $S$. endobioticum isolates. Numbers of clusters (K) between 1 and 6 were tested using the admixture model (Falush et al. 2003). In total, 10 independent runs of 100,000 iterations with a burn-in period of 50,000 MCMC (Markov Chain Monte Carlo) iterations were done. Results were postprocessed using Structure Harvester (Earl 2012). The $\Delta \mathrm{K}$ method of Evanno et al.
(2005) was used to evaluate the rate of change in the log probability of data between successive $\mathrm{K}$ values to infer the number of genetic clusters.

\section{RESULTS}

Microsatellite isolation, optimization of assays, and genotyping. The search for microsatellite motifs using MsatCommander version 1.0 .8 beta and specified criteria revealed 401 sequences containing 2- to 6-bp tandem repeats. From these sequences, 373 sequences were suitable for primer pair design (Table 2). The most common microsatellite motifs were dinucleotide repeats, which represented approximately $60 \%$ of all the microsatellites found. Trinucleotides, tetranucleotides, pentanucleotides, and hexanucleotides represented approximately $17,9,8$, and $5 \%$ of the motifs, respectively (Table 2).

From the suitable sequences, 62 primer pairs were selected based on length for optimization. From these 62 primer pairs, 38 produced amplicons in all three isolates used for optimization and 11 produced a pattern of presence and absence, while 13 did not produce a detectable amplicon. Following optimization, sequences containing the 62 selected microsatellites were checked in silico against an improved draft assembly of the Dutch pathotype 1 isolate MB42 genome. Loci not producing any amplicons and loci showing a pattern of presence and absence were not found in this new assembly, suggesting that they might not be derived from the $S$. endobioticum genome. Among the 38 loci producing amplicons in all three isolates used for optimization, all except 1 were found in the new assembly. Among the 37 loci found in the new assembly, based on local coverage, 5 were situated in multicopy regions of the genome and were discarded.

The primers selected in the optimization phase were used to genotype a larger panel of isolates from different countries (Table 1). Results revealed that 9 loci were monomorphic in all isolates tested, while 23 loci displayed polymorphisms. However, 2 of the polymorphic loci were difficult to score, leaving 21 polymorphic loci providing clear electropherograms in S. endobioticum (Table 3).

Genetic analyses. The 21 microsatellite loci developed in this study were moderately variable, displaying between 2.0 and 4.0

TABLE 1. Synchytrium endobioticum isolates and their genotypes at 21 polymorphic microsatellite loci ${ }^{\mathrm{a}}$

\begin{tabular}{|c|c|c|c|c|c|c|c|c|c|c|c|c|c|c|c|c|c|c|c|c|c|c|}
\hline \multirow{2}{*}{$\frac{\text { Isolate name }}{\text { NL-01 }}$} & \multirow{2}{*}{$\frac{\text { Year }}{\ldots}$} & \multirow{2}{*}{$\frac{\text { Origin }^{\mathrm{b}}}{\mathrm{NLD}}$} & \multirow{2}{*}{$\frac{\text { Path }^{\mathrm{c}}}{1}$} & \multirow{2}{*}{$\frac{\text { Source }^{d}}{\text { PRI }}$} & \multicolumn{2}{|c|}{$\mathrm{Se}-04$} & \multicolumn{2}{|c|}{ Se-14 } & \multicolumn{2}{|c|}{ Se-19 } & \multicolumn{2}{|c|}{$\mathrm{Se}-24$} & \multicolumn{2}{|c|}{ Se-25 } & \multicolumn{2}{|c|}{ Se-26 } & \multicolumn{2}{|c|}{ Se-29 } & \multicolumn{2}{|c|}{ Se-30 } & \multicolumn{2}{|c|}{ Se-36 } \\
\hline & & & & & 364 & 364 & 373 & 373 & 292 & 292 & 406 & 406 & 297 & 297 & 182 & 182 & 395 & 395 & 402 & 402 & 344 & 344 \\
\hline NL-02 & $\ldots$ & NLD & 1 & PRI & 364 & 364 & 373 & 373 & 292 & 292 & 406 & 406 & 297 & 299 & 182 & 182 & 395 & 395 & 402 & 402 & 346 & 346 \\
\hline NL-03 & $\ldots$ & NLD & 6 & PRI & 364 & 364 & 373 & 373 & 292 & 292 & 406 & 406 & 297 & 297 & 182 & 182 & 395 & 395 & 402 & 402 & 346 & 346 \\
\hline NL-04 & $\ldots$ & NLD & 18 & PRI & 328 & 328 & 373 & 373 & 296 & 296 & 402 & 406 & 301 & 301 & 182 & 182 & 367 & 367 & 402 & 402 & 346 & 346 \\
\hline NL-05 & 1987 & NLD & 2 & PRI & 364 & 364 & 371 & 373 & 292 & 292 & 402 & 406 & 297 & 297 & 182 & 182 & 395 & 400 & 402 & 402 & 346 & 346 \\
\hline DE-01 & $\ldots$ & Germany & 2 & PRI & 364 & 364 & 371 & 371 & 292 & 292 & 402 & 402 & 297 & 297 & 182 & 182 & 395 & 395 & 402 & 402 & 346 & 346 \\
\hline DE-02 & $\ldots$ & Germany & 6 & PRI & 364 & 364 & 373 & 373 & 292 & 292 & 406 & 406 & 297 & 297 & 173 & 182 & 395 & 395 & 402 & 402 & 346 & 346 \\
\hline DE-03 & $\ldots$ & Germany & 1 & PRI & 364 & 364 & 373 & 373 & 292 & 292 & 406 & 406 & 299 & 299 & 182 & 182 & 395 & 395 & 402 & 402 & 346 & 346 \\
\hline DE-04 & $\ldots$ & Germany & 2 & PRI & 364 & 364 & 371 & 371 & 292 & 292 & 406 & 406 & 297 & 297 & 182 & 182 & 395 & 395 & 402 & 402 & 346 & 346 \\
\hline DE-05 & $\ldots$ & Germany & 18 & PRI & 328 & 328 & 373 & 373 & 296 & 296 & 402 & 402 & 301 & 301 & 182 & 182 & 367 & 367 & 402 & 402 & 346 & 346 \\
\hline UK-01 & $\ldots$ & UK & 1 & PRI & 328 & 328 & 373 & 373 & 292 & 292 & 402 & 406 & 299 & 299 & 182 & 182 & 381 & 381 & 385 & 396 & 346 & 346 \\
\hline UK-02 & & UK & 1 & PRI & 328 & 328 & 373 & 373 & 292 & 292 & 406 & 406 & 297 & 299 & 182 & 182 & 381 & 381 & 385 & 396 & 346 & 346 \\
\hline UK-03 & 2011 & UK & $\ldots$ & SASA & 364 & 364 & 373 & 373 & 292 & 292 & 406 & 406 & 297 & 299 & 173 & 173 & 395 & 395 & 396 & 396 & 346 & 346 \\
\hline UK-04 & 2012 & UK & $\ldots$ & SASA & 328 & 328 & 373 & 373 & 292 & 292 & 406 & 406 & 299 & 299 & 182 & 182 & 395 & 395 & 396 & 396 & 346 & 346 \\
\hline CA-01 & 2000 & PEI & 6 & CFIA & 364 & 364 & 373 & 373 & 292 & 292 & 402 & 402 & 297 & 297 & 182 & 182 & 395 & 395 & 355 & 402 & 346 & 346 \\
\hline CA-02 & 2012 & PEI & $\ldots$ & CFIA & 364 & 364 & 373 & 373 & 292 & 292 & 402 & 402 & 297 & 297 & 182 & 182 & 395 & 395 & 402 & 402 & 344 & 344 \\
\hline CA-03 & 2012 & PEI & $\ldots$ & CFIA & 364 & 364 & 373 & 373 & 292 & 292 & 402 & 402 & 297 & 297 & 182 & 182 & 395 & 395 & 402 & 402 & 344 & 344 \\
\hline CA-04 & 2014 & PEI & $\ldots$ & CFIA & 364 & 364 & 373 & 373 & 292 & 292 & 402 & 402 & 297 & 297 & 182 & 182 & 395 & 395 & 402 & 402 & 344 & 344 \\
\hline CA-05 & $\ldots$ & NFL & Mixed & AAFC & 364 & 364 & 373 & 373 & 292 & 292 & 402 & 402 & 297 & 297 & 182 & 182 & 395 & 395 & 402 & 402 & 344 & 344 \\
\hline CA-06 & $\ldots$ & NFL & Mixed & AAFC & 364 & 364 & 373 & 373 & 292 & 292 & 402 & 402 & 297 & 297 & 182 & 182 & 395 & 395 & 402 & 402 & 344 & 344 \\
\hline CA-07 & $\ldots$ & NFL & Mixed & AAFC & 364 & 364 & 373 & 373 & 292 & 292 & 402 & 402 & 297 & 297 & 182 & 182 & 395 & 395 & 402 & 402 & 316 & 316 \\
\hline CA-08 & $\ldots$ & NFL & Mixed & AAFC & 364 & 364 & 373 & 373 & 292 & 292 & 402 & 402 & 297 & 297 & 182 & 182 & 395 & 395 & $\begin{array}{l}402 \\
\text { (cont }\end{array}$ & 402 & 316 & 316 \\
\hline
\end{tabular}

a Data unknown indicated by "...".

b NLD = The Netherlands; UK = the United Kingdom; PEI = Prince Edward Island, Canada; and NFL = Newfoundland, Canada.

c Pathotype. Mixed = isolates presenting different pathotypes were pooled to increase yield.

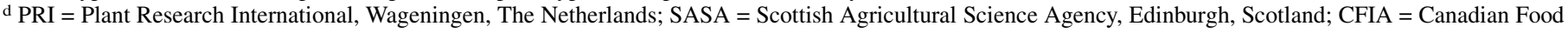
Inspection Agency, Prince Edward Island, Canada; and AAFC = Agriculture and Agri-Food Canada, Ottawa, Canada. 
alleles/locus (mean 2.6) (Table 3). This moderate level of variation was also reflected in the mean 1-D value (0.343) (Table 3 ), indicating that two randomly sampled individuals had a good probability of sharing alleles at these markers. Only two loci displayed a low expected heterozygosity $(\mathrm{Se}-41=0.089$ and Se-58 $=0.089)$ while three loci displayed high expected heterozygosity (Se-24 $=0.998$, Se-46 $=0.926$, and Se-47 $=0.926$ ). The mean expected heterozygosity over all loci was 0.589 (Table 3 ). Overall, alleles seemed to be relatively evenly distributed within loci, with not many alleles presenting minor frequencies (mean 0.687) (Table 3). The genotype accumulation curve indicated that the 21 loci developed were powerful enough to discriminate between the different $S$. endobioticum isolates included in our panel. In general, $90 \%$ of the multilocus genotypes were detected using approximately 12 markers, while most of the genotypes were detected using 15 or more markers (Fig. 1).

The microsatellite loci detected 19 multilocus genotypes out of the 22 samples tested. Three Canadian isolates (namely, CA-02, CA-03, and CA-04) discovered in 2012 and 2014 in PEI presented an identical genotype. CA-01, the fourth Canadian isolate discovered in 2000 in PEI, was different from the three others at seven loci (Table 1). For all the isolates genotyped, the expected heterozygosity was high (0.983). Although a similar pathotype was found for some genetically closely related isolates such as NL-04 and DE-05 (pathotype 18) and NL-03 and DE-02 (pathotype 6), isolates presenting the same pathotype mostly displayed different genotypes, indicating no clear association between genotypes and pathotypes (Table 1).

The two main axes of the PCA performed using Bruvo's genetic distance allowed the identification of three main genetic clusters of $S$. endobioticum isolates (Fig. 2). The first cluster, concentrated mostly in the negative values of principal component (PC) 1 and the positive values of PC2, comprised the Canadian isolates from PEI and Newfoundland, as well as two isolates from The Netherlands (Fig. 2). Within this cluster, isolate CA-01 (discovered in 2000 in PEI) seemed closer to the two Netherlands isolates than the other Canadian isolates (Fig. 2). This first cluster comprised isolates displaying pathotypes 1,2 , and 6 and also a mix of pathotypes. The second cluster, concentrated predominantly in the negative values of PC1 and the negative values of PC2, comprised isolates from The Netherlands and Germany and one isolate from the United Kingdom (Fig. 2). This cluster comprised isolates displaying pathotypes 1,2, and 6. The third cluster, concentrated in the positive values of PC1, was composed of isolates from The Netherlands, Germany, and the United Kingdom (Fig. 2). This cluster comprised isolates displaying pathotypes 1 and 18. Further clustering could be observed within this genetic group. Isolates NL-04 and DE-05, both presenting pathotype 18 , formed one subcluster while UK-01, UK-02, and UK-04 from the United Kingdom formed the other subcluster (Fig. 2). Except for the Canadian isolates that clustered together in the first genetic group, the main genetic clusters observed in this PCA analysis suggest that the $S$. endobioticum isolates within our panel did not cluster by geographic origin or by pathotype.

Both phylogenetic trees generated indicated similar results (Fig. 3A and B). Canadian isolates from PEI and Newfoundland provinces formed a supported group (93.2 and 52.0\% bootstrap values for Cavalli-Sforza and Edwards' and Bruvo's distances, respectively), with the exception of CA-01, discovered in 2000 on PEI. Indeed, this isolate grouped mostly with two isolates from The Netherlands but this grouping was not supported in both phylogenetic hypotheses (Fig. 3A and B). The other main supported group was similar to the third genetic cluster detected by the PCA analysis, with isolates from The Netherlands, Germany, and the United Kingdom grouping together $(69.1$ and $86 \%$ bootstrap values for Cavalli-Sforza and Edwards' and Bruvo's distances, respectively) (Fig. 3A and B). The phylogenetic trees did not support grouping of S. endobioticum isolates by pathotypes or geographic origin, except for the Canadian isolates and the grouping of the two isolates presenting pathotype 18 .

The Structure analysis, supported by the $\Delta \mathrm{K}$ analysis, indicated that the correct minimum number of genetic clusters in our panel was three (Fig. 4A and B). Overall, composition of the clusters was similar to the results of the PCA analysis. The main difference was that Canadian isolate CA-01 did not cluster with the other Canadian isolates from both PEI and Newfoundland but, instead, clustered

TABLE 1. (continued from preceding page)

\begin{tabular}{|c|c|c|c|c|c|c|c|c|c|c|c|c|c|c|c|c|c|c|c|c|c|c|c|}
\hline \multicolumn{2}{|c|}{$\mathrm{Se}-37$} & \multicolumn{2}{|c|}{ Se-38 } & \multicolumn{2}{|c|}{$\mathrm{Se}-40$} & \multicolumn{2}{|c|}{$\mathrm{Se}-41$} & \multicolumn{2}{|c|}{$\mathrm{Se}-44$} & \multicolumn{2}{|c|}{$\mathrm{Se}-46$} & \multicolumn{2}{|c|}{$\mathrm{Se}-47$} & \multicolumn{2}{|c|}{$\mathrm{Se}-48$} & \multicolumn{2}{|c|}{$\mathrm{Se}-49$} & \multicolumn{2}{|c|}{ Se-58 } & \multicolumn{2}{|c|}{ Se-60 } & \multicolumn{2}{|c|}{ Se-62 } \\
\hline 370 & 370 & 297 & 297 & 384 & 384 & 216 & 216 & 350 & 350 & 383 & 383 & 300 & 300 & 382 & 382 & 260 & 260 & 395 & 395 & 364 & 364 & 281 & 283 \\
\hline 370 & 370 & 293 & 297 & 382 & 384 & 216 & 216 & 339 & 350 & 374 & 383 & 300 & 300 & 382 & 382 & 260 & 260 & 395 & 395 & 364 & 364 & 281 & 283 \\
\hline 368 & 368 & 293 & 293 & 384 & 384 & 216 & 216 & 339 & 339 & 383 & 383 & 297 & 300 & 385 & 385 & 260 & 260 & 395 & 395 & 364 & 364 & 283 & 283 \\
\hline 370 & 370 & 295 & 295 & 382 & 382 & 216 & 216 & 350 & 350 & 374 & 383 & 297 & 300 & 382 & 382 & 260 & 260 & 395 & 395 & 328 & 328 & 283 & 283 \\
\hline 370 & 370 & 297 & 297 & 382 & 384 & 216 & 224 & 350 & 350 & 383 & 383 & 300 & 300 & 382 & 382 & 260 & 260 & 395 & 395 & 364 & 364 & 283 & 283 \\
\hline 368 & 368 & 293 & 293 & 382 & 382 & 216 & 216 & 350 & 350 & 374 & 383 & 297 & 297 & 385 & 385 & 260 & 260 & 395 & 395 & 328 & 364 & 283 & 283 \\
\hline 368 & 368 & 293 & 293 & 384 & 384 & 216 & 216 & 339 & 339 & 383 & 383 & 297 & 297 & 385 & 385 & 260 & 260 & 395 & 395 & 364 & 364 & 283 & 283 \\
\hline 370 & 370 & 293 & 297 & 382 & 382 & 216 & 216 & 350 & 350 & 374 & 383 & 300 & 300 & 382 & 382 & 260 & 260 & 395 & 395 & 364 & 364 & 283 & 283 \\
\hline 368 & 368 & 293 & 297 & 382 & 382 & 216 & 216 & 350 & 350 & 374 & 374 & 297 & 297 & 388 & 388 & 260 & 260 & 395 & 395 & 364 & 364 & 283 & 283 \\
\hline 370 & 370 & 295 & 295 & 382 & 382 & 216 & 216 & 350 & 350 & 374 & 374 & 297 & 297 & 382 & 382 & 260 & 260 & 395 & 395 & 328 & 328 & 283 & 283 \\
\hline 370 & 370 & 293 & 293 & 382 & 382 & 216 & 216 & 333 & 333 & 374 & 374 & 297 & 297 & 382 & 382 & 260 & 260 & 393 & 395 & 328 & 328 & 283 & 283 \\
\hline 370 & 370 & 293 & 293 & 382 & 382 & 216 & 216 & 333 & 350 & 374 & 374 & 297 & 297 & 382 & 382 & 260 & 260 & 395 & 395 & 328 & 328 & 283 & 283 \\
\hline 368 & 370 & 300 & 300 & 382 & 384 & 216 & 216 & 333 & 333 & 383 & 383 & 300 & 300 & 382 & 382 & 260 & 260 & 395 & 395 & 364 & 364 & 283 & 283 \\
\hline 368 & 368 & 293 & 293 & 382 & 382 & 216 & 216 & 333 & 333 & 374 & 374 & 297 & 297 & 382 & 382 & & & 395 & 395 & 328 & 328 & 283 & 283 \\
\hline 370 & 370 & 297 & 297 & 386 & 386 & 216 & 216 & 350 & 350 & 383 & 383 & 300 & 300 & 382 & 382 & $2 \overline{6} 0$ & $2 \overline{6} 0$ & 395 & 395 & 364 & 364 & 276 & 283 \\
\hline 370 & 370 & 293 & 293 & 384 & 384 & 216 & 216 & 350 & 350 & 374 & 374 & 300 & 300 & 382 & 382 & 263 & 263 & 395 & 395 & 364 & 364 & 283 & 283 \\
\hline 370 & 370 & 293 & 293 & 384 & 384 & 216 & 216 & 350 & 350 & 374 & 374 & 300 & 300 & 382 & 382 & 263 & 263 & 395 & 395 & 364 & 364 & 283 & 283 \\
\hline 370 & 370 & 293 & 293 & 384 & 384 & 216 & 216 & - & - & 374 & 374 & 300 & 300 & 382 & 382 & 263 & 263 & 395 & 395 & 364 & 364 & 283 & 283 \\
\hline 370 & 370 & 293 & 297 & 384 & 384 & 216 & 216 & $3 \overline{5} 0$ & $3 \overline{5} 0$ & 374 & 374 & 300 & 300 & 382 & 382 & 263 & 263 & 395 & 395 & 364 & 364 & 283 & 283 \\
\hline 370 & 370 & 293 & 293 & 384 & 384 & 216 & 216 & 350 & 350 & 374 & 374 & 300 & 300 & 382 & 382 & 263 & 263 & 395 & 395 & 364 & 364 & 283 & 283 \\
\hline 370 & 370 & 293 & 297 & 384 & 384 & 216 & 216 & 350 & 350 & 374 & 374 & 300 & 300 & 382 & 382 & 263 & 263 & 395 & 395 & 364 & 364 & 283 & 283 \\
\hline 370 & 370 & 293 & 297 & 384 & 384 & 216 & 216 & 350 & 350 & 374 & 374 & 300 & 300 & 382 & 382 & 263 & 263 & 395 & 395 & 364 & 364 & 283 & 283 \\
\hline
\end{tabular}


with isolates from The Netherlands, Germany, and the United Kingdom (Fig. 4B). Composition of the clusters was also similar to the grouping suggested by the phylogenetic analyses for the white and gray clusters (Fig. 4B). This analysis did not support clustering of the isolates by geographic origin (excepted for the Canadian isolates) or pathotypes.

TABLE 2. Microsatellite search criteria and results for assembled contigs of Synchytrium endobioticum MB42 pathotype 1 genome

\begin{tabular}{lcccc}
\hline & Repeats $^{\mathrm{a}}$ & Sequences $^{\mathrm{b}}$ & Primer pairs $^{\mathrm{c}}$ & Loci tested $^{\mathrm{d}}$ \\
\hline Dinucleotide & 8 & 242 & 231 & 31 \\
Trinucleotide & 8 & 69 & 68 & 16 \\
Tetranucleotide & 6 & 38 & 35 & 2 \\
Pentanucleotide & 6 & 33 & 21 & 6 \\
Hexanucleotide & 6 & 19 & 18 & 7 \\
Total & $\ldots$ & 401 & 373 & 62
\end{tabular}

${ }^{a}$ Minimum number of repeats.

b Number of sequences with tandem repeats.

c Number of sequences allowing for primer pair design.

${ }^{d}$ Number of loci selected for testing.

\section{DISCUSSION}

In this study, 21 polymorphic microsatellite loci were developed from whole-genome sequence data for the potato wart pathogen S. endobioticum. These new markers allowed for the characterization of a panel of $S$. endobioticum isolates coming from Canada and Europe. Results indicated that most isolates within our panel were genetically distinct, and that the genetic similarities observed between isolates was not the result of geographic origin or pathotypes, with the exception of most Canadian isolates and two isolates presenting pathotype 18 .

From the 62 microsatellite loci which were chosen for optimization, 21 displayed polymorphism in our panel of $S$. endobioticum isolates. These markers allowed us to distinguish 19 multilocus genotypes out of the 22 isolates genotyped (Table 1) despite the moderate level of variation displayed by loci. Also, no isolate exhibited three alleles at any of the loci used (Table 1), suggesting that the S. endobioticum isolates included in our panel were diploid, as expected for DNA extracted from resting sporangia (Alexopoulos et al. 1996; Hampson 1993). Molecular markers previously developed for S. endobioticum used the internal transcribed spacer regions of the rDNA (Niepold and

TABLE 3. Primers used for the amplification of polymorphic microsatellite loci in Synchytrium endobioticum

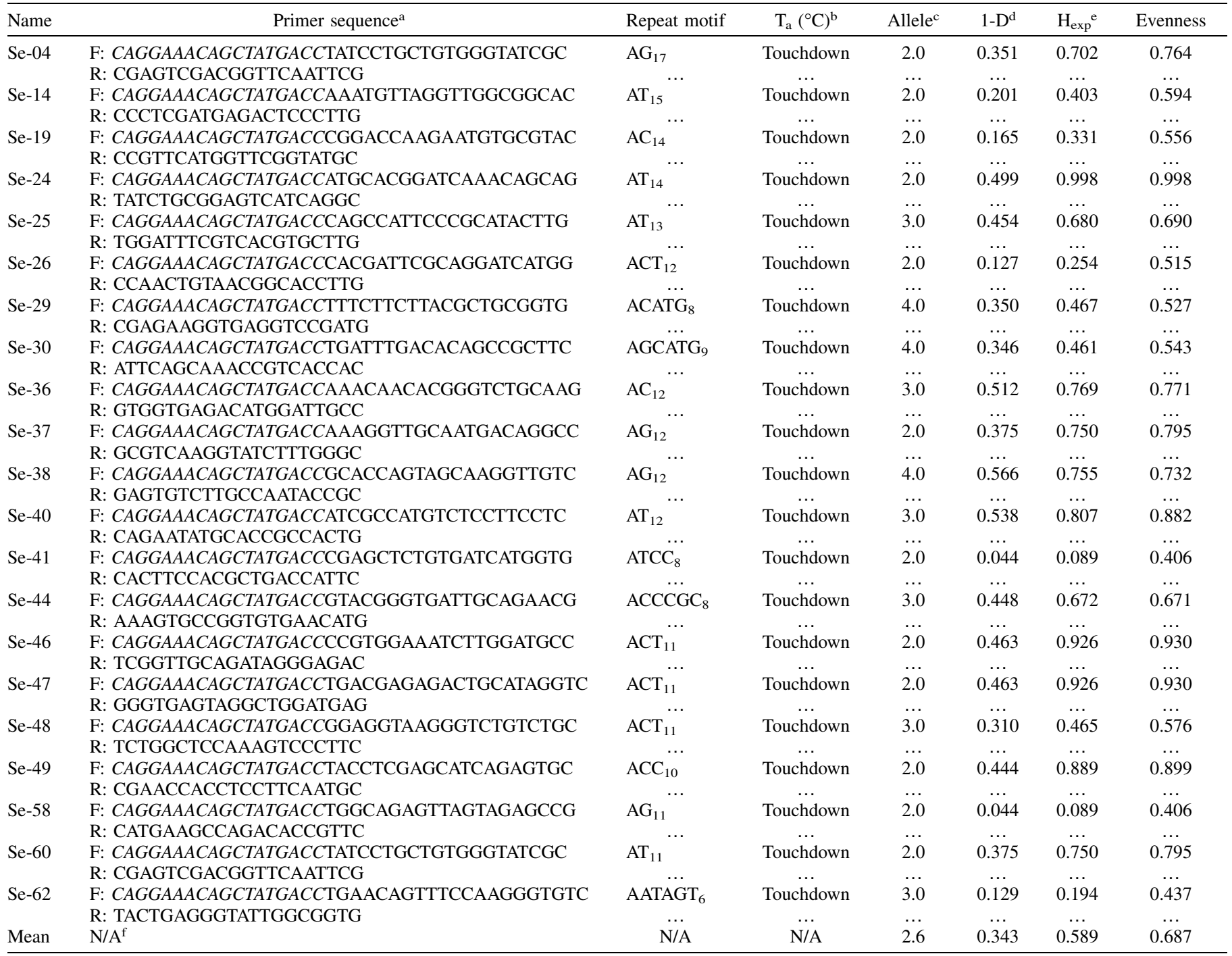

a The M13 tag-forward sequence is in italics.

b Annealing temperature. Touchdown $=\mathrm{T}_{\mathrm{a}}$ going from 60 to $50^{\circ} \mathrm{C}$ (dropping $0.5^{\circ} \mathrm{C}$ per cycle).

c Number of alleles.

d Simpson's index of diversity.

e Expected heterozygosity.

${ }^{\mathrm{f}} \mathrm{N} / \mathrm{A}=$ not applicable. 
Stachewicz 2004; Smith et al. 2014; van den Boogert et al. 2005; van Gent-Pelzer et al. 2010) or the 18S rDNA region (Abdullahi et al. 2005). These regions are useful for species-specific diagnostics but do not display intraspecific variation in S. endobioticum and cannot be used for genotyping (Smith et al. 2014; van den Boogert et al. 2005). The IGS region of rDNA has also been used to investigate intraspecific variation in the potato wart pathogen, without success (Smith et al. 2014). The microsatellite markers

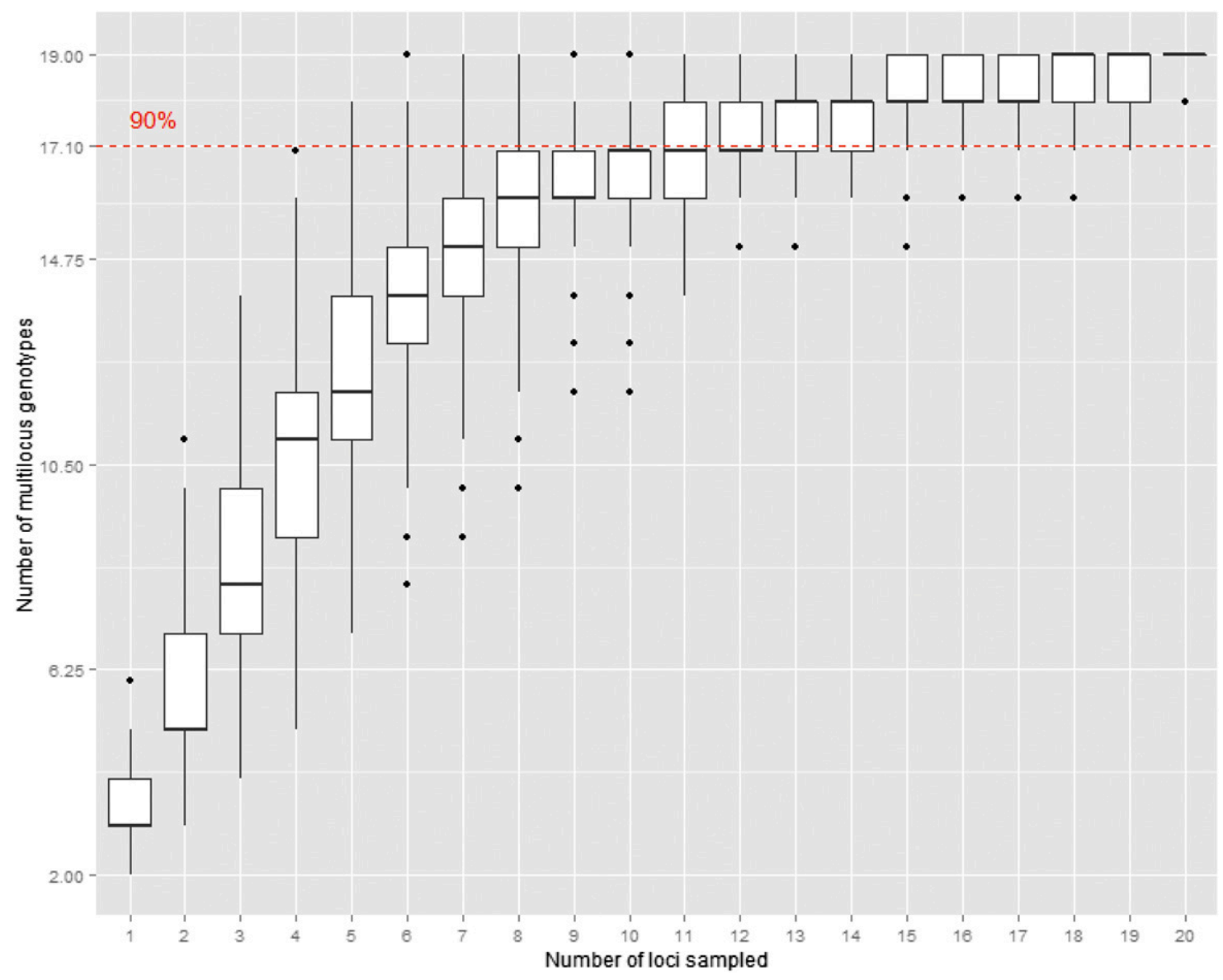

Fig. 1. Genotype accumulation curve built with 1,000 resampling for the 21 microsatellite loci polymorphic in Synchytrium endobioticum.

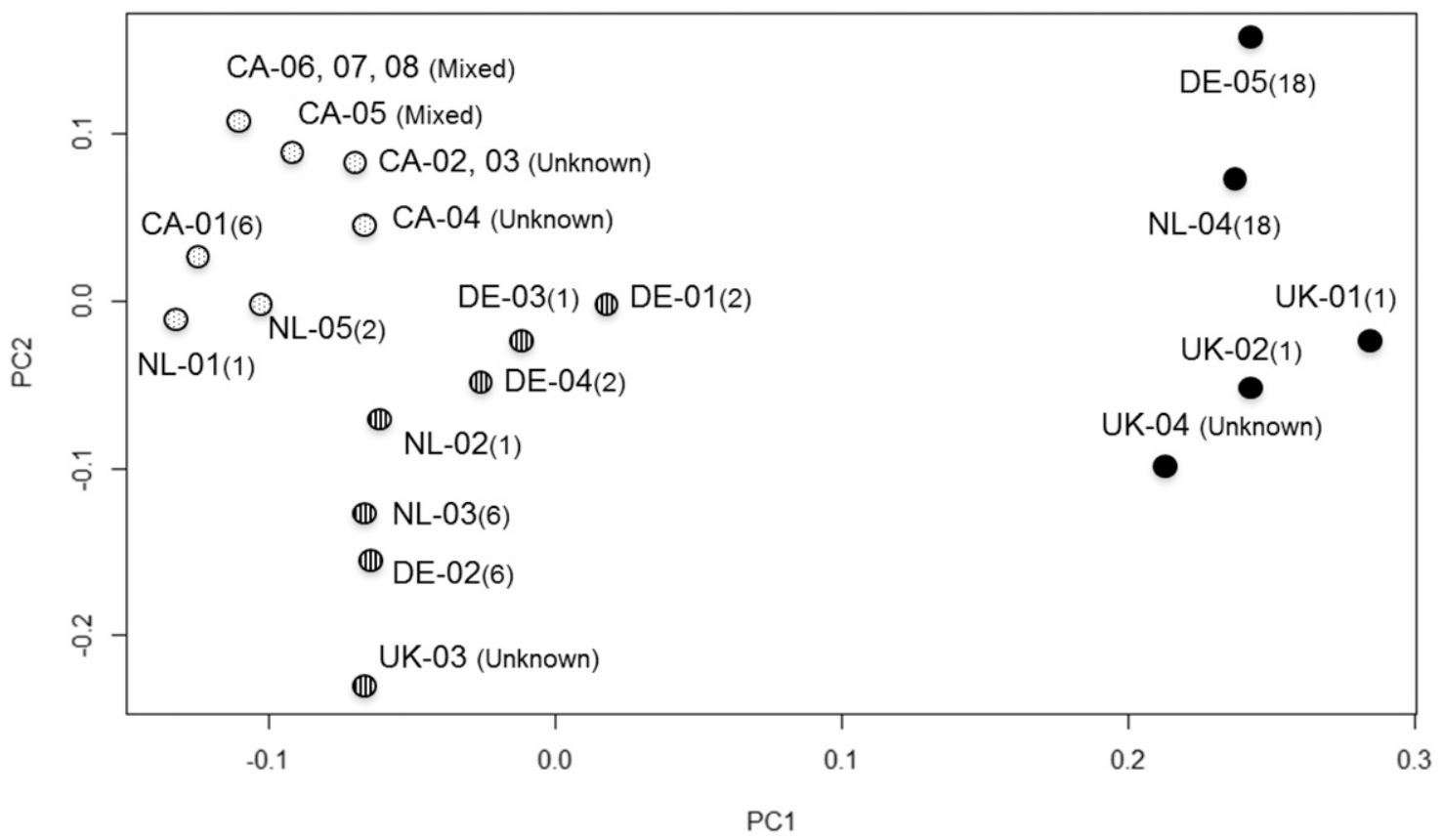

Fig. 2. Principal component analysis performed with Bruvo's genetic distance. Genetic clusters are represented by patterned circles (dots $=$ genetic cluster 1 , stripes $=$ genetic cluster 2 , and black $=$ genetic cluster 3). Pathotype is indicated in parentheses after the isolate name. PC1 and PC2 indicates principal component axis 1 and 2 , respectively. 
developed in this study for the first time allow assessment of the intraspecific variation in S. endobioticum.

Eight isolates from Canada were genotyped with the 21 markers developed in this study. Four of these isolates came from Newfoundland while the other four came from PEI. Three of the PEI isolates, discovered in 2012 and 2014, were identical, suggesting that they were clones (Table 1). The fourth PEI isolate (discovered in 2000) was genetically different from the other three PEI isolates. All the analyses performed (PCA, neighbor-joining trees, and Structure) suggested that the three identical PEI isolates were genetically similar to the four isolates from Newfoundland, while the PEI isolate discovered in 2000 showed more genetic similarities to isolates from Europe than from Canada (Figs. 2 to 4).

The genetic clustering of nearly all Canadian isolates point toward Newfoundland, where potato wart has been present for many decades, as the source population for the introduction of this pathogen on PEI. The genetic differences observed between PEI isolates from 2000 and 2012 to 2014 suggest two different introduction events on PEI from Newfoundland rather than suggesting a recent dispersion of $S$. endobioticum from Europe. The fact that the PEI isolate from 2000 shows more genetic similarities with isolates from Europe than Canada probably only reflects a lack of sampling from Newfoundland. It is doubtful that a recent introduction from a European country might have occurred because of the severe quarantine and phytosanitary measures applied by Canada and European countries (Hampson 1993; Obidiegwu et al. 2014; Smith et al. 1997). Anecdotal information gathered in 2000 pointed toward tubers from Newfoundland grown in the infected area of the PEI field many years ago as the likely source of this introduction onto the island (De Boer 2001). A better

A

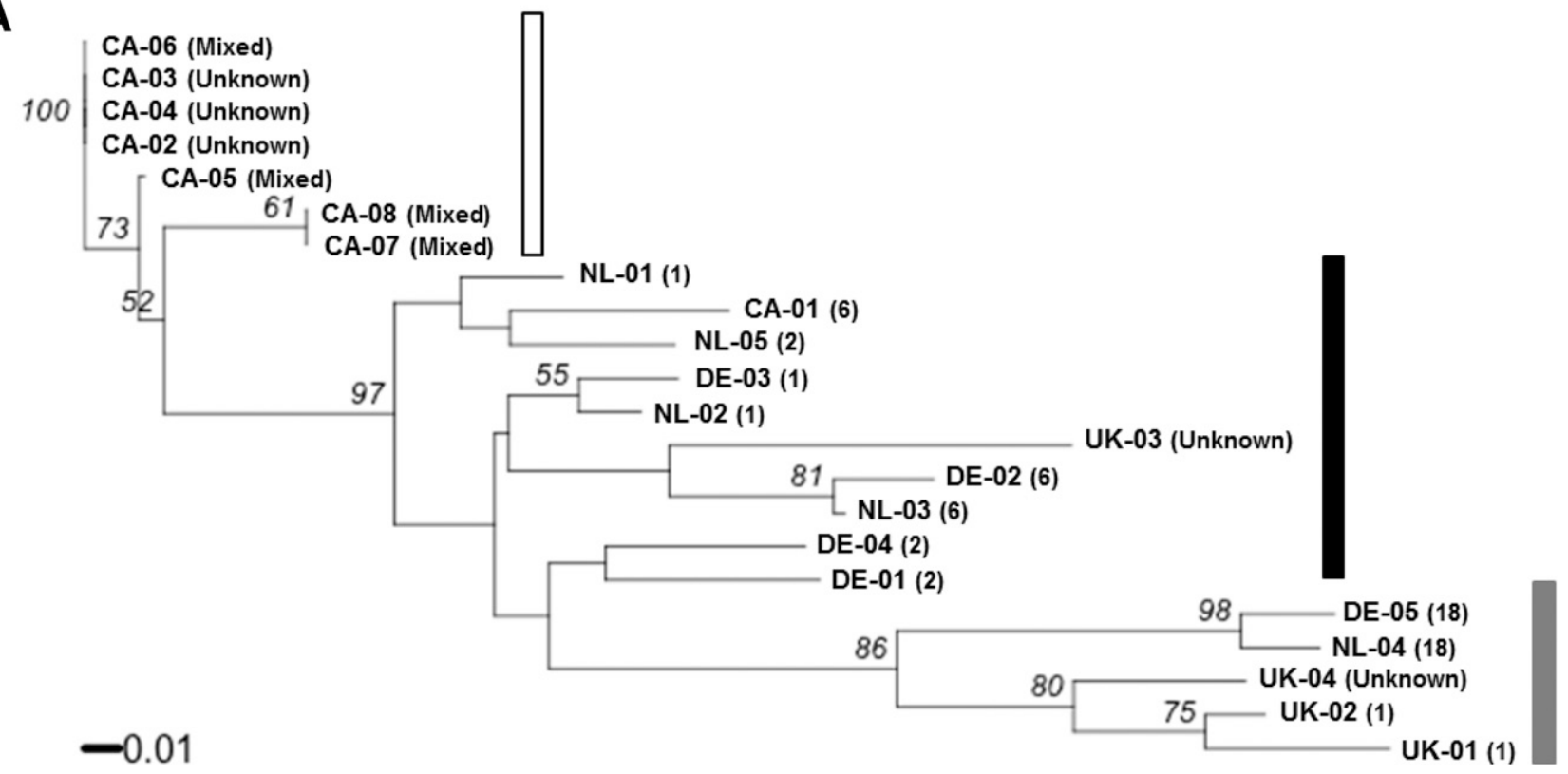

B

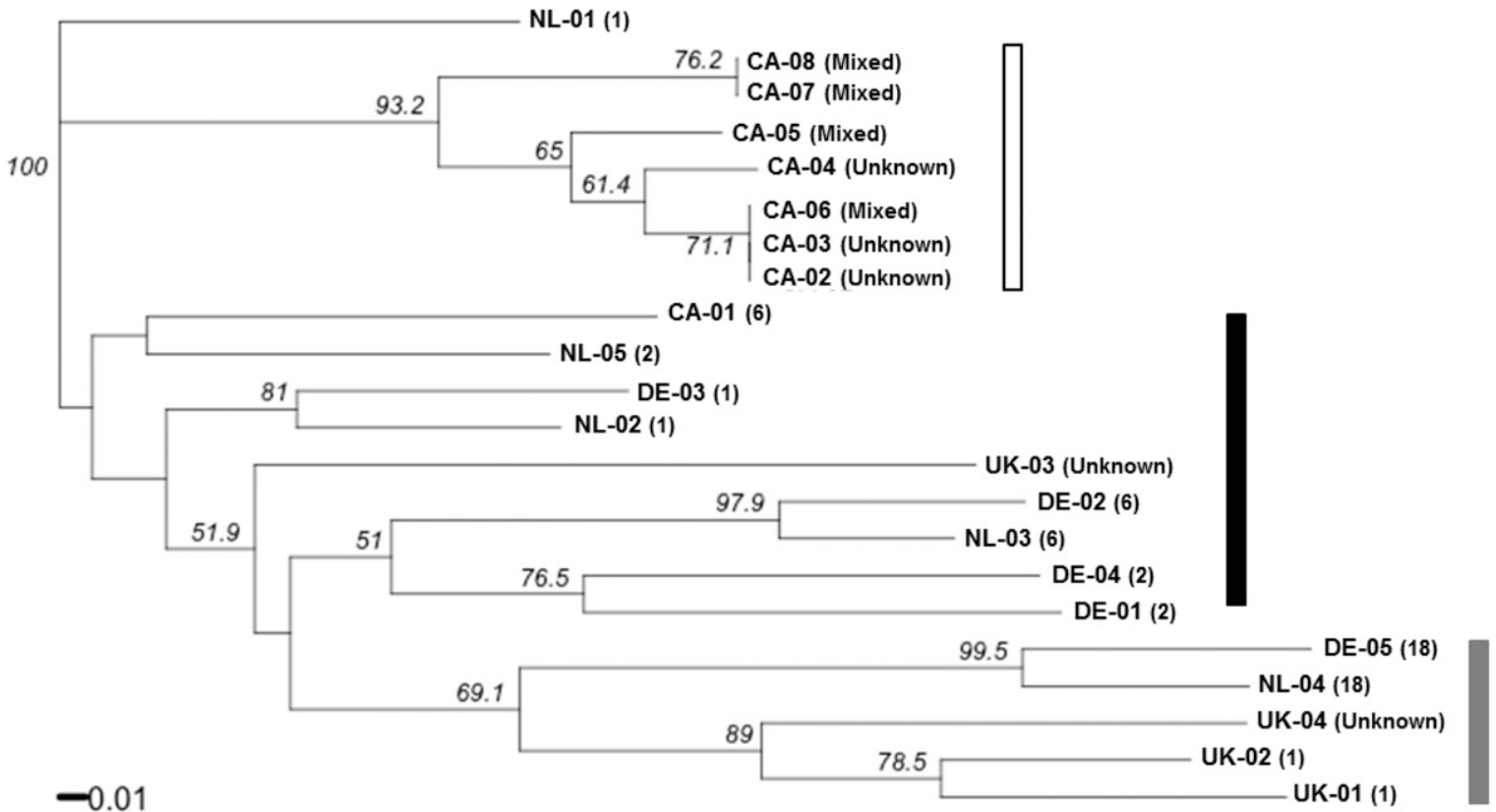

Fig. 3. Neighbor-joining phylogenetic trees built with A, Bruvo's and B, Cavalli-Sforza and Edwards' genetic distances. Gray shades represent genetic clusters as defined by the Structure analysis. Pathotype is indicated in parentheses after the isolate name. 
characterization of the source population of potato wart from Newfoundland, including more isolates, would help shed light on these results and give a better understanding of the potato wart introductions onto PEI.

With the exception of most of the Canadian samples, clustering of the $S$. endobioticum isolates included in our panel did not reflect the geographic origin of the samples (Figs. 2 to 4 ). This result most likely reflects the historical spread of the pathogen around the world. Indeed, potato wart disease is thought to have spread widely through international trade of infected tubers or soil before quarantine measures and legislation were put into place at the beginning of the 20th century (Hampson 1993; Obidiegwu et al. 2014; Smith et al. 1997). The same isolate, or genetically close isolates, might have been spread to different countries during this period, explaining the clustering patterns observed in our study. Collecting and genotyping more samples coming from a wider panel of infected countries around the world, including the center of origin, would help get a better idea of the genetic diversity present within the species and to validate the dispersion patterns inferred through historical documents.
Our results did not indicate a clear association between genotypes and pathotypes in our samples (Table 1). Indeed, isolates presenting the same pathotype generally displayed different genotypes. This finding is not necessarily surprising because microsatellites are generally assumed to reflect neutral variation (Ellegren 2004). Although specific pathogenicity mechanisms are not known in S. endobioticum pathotypes, variation is most likely under selective processes, as observed in other plant pathogens (Sacristán and García-Arenal 2008). Thus, isolates displaying different genotypes but presenting the same pathotype could be the result of convergent evolution during host-pathogen interactions. Assessing the pathotype of an isolate is difficult and requires qualitative assessment that may lead to erroneous determination. It is possible that the reassessment of the pathotypes for the strains that do not follow the pathotype-genotype correlation could show an improved usefulness of microsatellite analysis for pathotyping compared with what was found in this study.

The approach used in this study for microsatellite mining allowed the development of polymorphic markers for a plant pathogen that

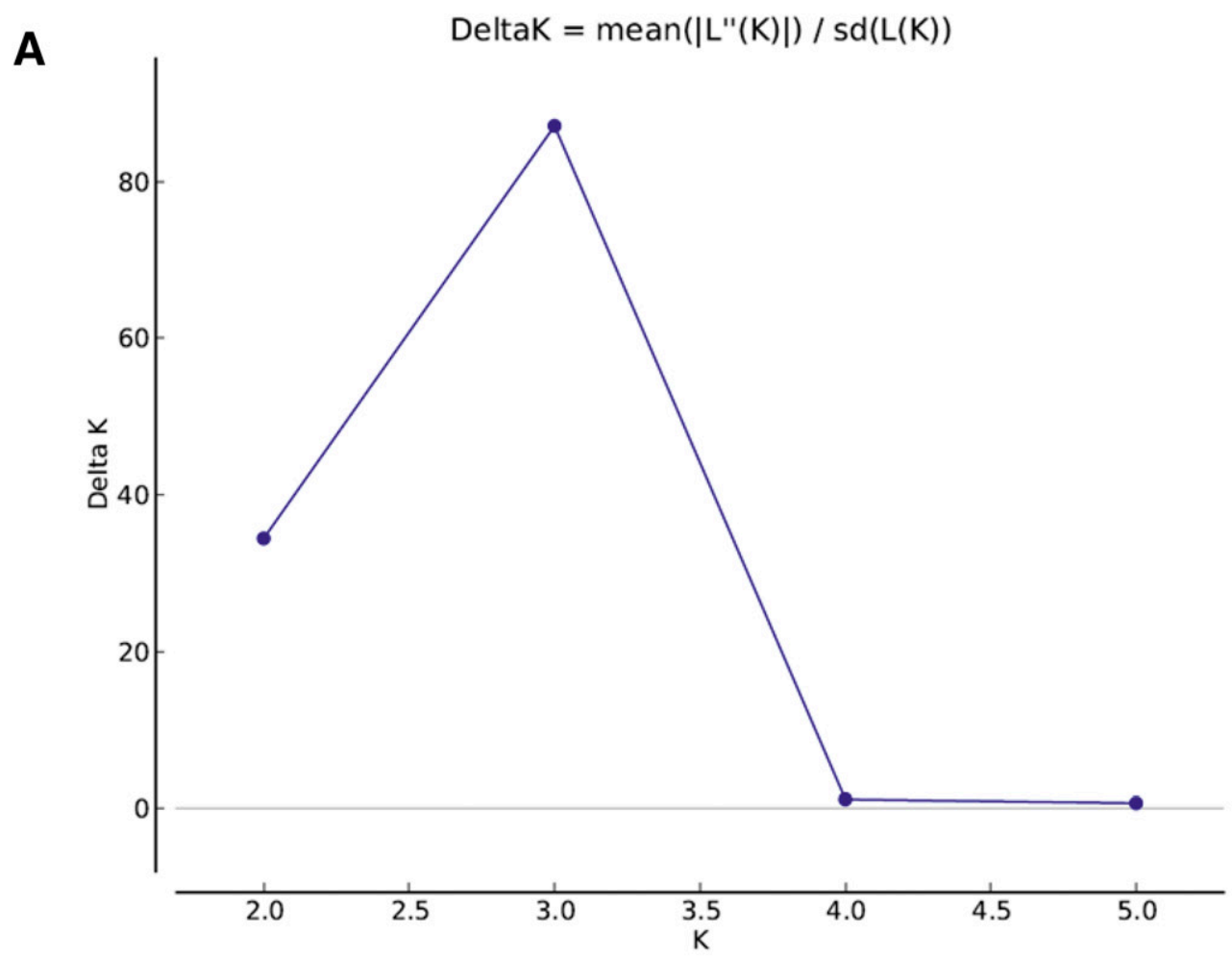

B

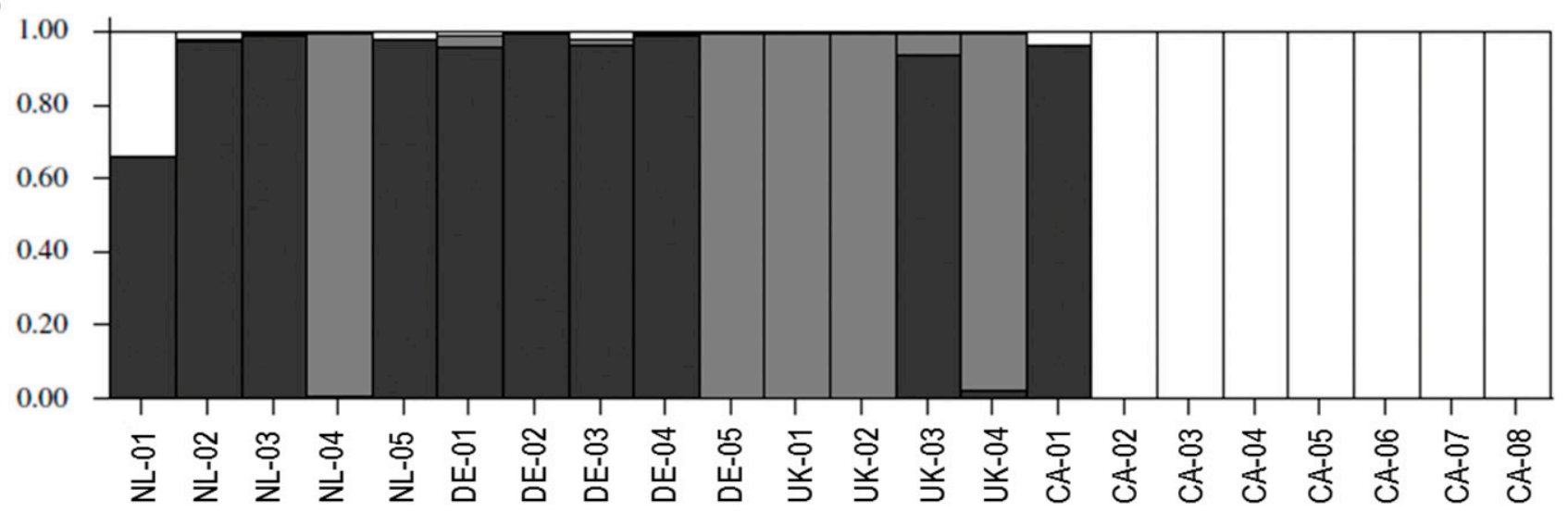

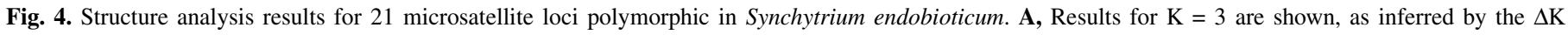
analysis using Structure Harvester. B, Each different shade represents a genetic cluster as defined by the Structure analysis. 
threatens potato production worldwide. These markers were used to assess the genetic diversity of potato wart at the intraspecific level for the first time and will certainly contribute to a better understanding of the evolutionary history of this pathogen in the years to come.

\section{ACKNOWLEDGMENTS}

We thank M. Newton, D. Shearlaw, R. Vandenbeek, and A. Brar (Pathogen Identification Research Lab, CFIA, Ottawa, Canada) and M. van Gent-Pelzer (Wageningen University and Research Center, Wageningen, The Netherlands) for technical help; and T. Rintoul (AAFC, Ottawa, Canada) for editing the manuscript. Financial support was provided by the Canadian Safety and Security Program (project number CRTI 09-462RD) and by the Dutch Ministry of Economic affairs.

\section{LITERATURE CITED}

Abdullahi, I., Koerbler, M., Stachewicz, H., and Winter, S. 2005. The $18 \mathrm{~S}$ rDNA sequence of Synchytrium endobioticum and its utility in microarrays for the simultaneous detection of fungal and viral pathogens of potato. Appl. Microbiol. Biotechnol. 68:368-375.

Alexopoulos, C. J., Mims, C. W., and Blackwell, M. M. 1996. Introductory Mycology, 4th ed. Wiley, New York.

Arnaud-Haond, S., Duarte, C. M., Alberto, F., and Serrao, E. A. 2007. Standardizing methods to address clonality in population studies. Mol. Ecol. 16: 5115-5139.

Baayen, R. P., Cochius, G., Hendriks, H., Meffert, J. P., Bakker, J., Bekker, M., van den Boogert, P. H. J. F., Stachewicz, H., and van Leeuwen, G. C. M. 2006. History of potato wart disease in Europe-A proposal for harmonisation in defining pathotypes. Eur. J. Plant Pathol. 116:21-31.

Bruvo, R., Michiels, N. K., D'Souza, T. G., and Schulenburg, H. 2004. A simple method for the calculation of microsatellite genotype distances irrespective of ploidy level. Mol. Ecol. 13:2101-2106.

Cavalli-Sforza, L. L., and Edwards, A. W. 1967. Phylogenetic analysis. Models and estimation procedures. Am. J. Hum. Genet. 19:233-257.

Clark, L. V., and Jasieniuk, M. 2011. POLYSAT: An R package for polyploid microsatellite analysis. Mol. Ecol. Resour. 11:562-566.

De Boer, S. 2001. Occurrence of potato wart caused by Synchytrium endobioticum on Prince Edward Island, Canada. Plant Dis. 85:1292.

Earl, D. A. 2012. STRUCTURE HARVESTER: A website and program for visualizing STRUCTURE output and implementing the Evanno method. Conserv. Genet. Resour. 4:359-361.

Ellegren, H. 2000. Microsatellite mutations in the germline: Implications for evolutionary inference. Trends Genet. 16:551-558.

Ellegren, H. 2004. Microsatellites: Simple sequences with complex evolution. Nat. Rev. Genet. 5:435-445.

Evanno, G., Regnaut, S., and Goudet, J. 2005. Detecting the number of clusters of individuals using the software STRUCTURE: A simulation study. Mol. Ecol. 14:2611-2620.

Faircloth, B. C. 2008. Msatcommander: Detection of microsatellite repeat arrays and automated, locus-specific primer design. Mol. Ecol. Resour. 8:92-94.

Falush, D., Stephens, M., and Pritchard, J. K. 2003. Inference of population structure using multilocus genotype data: Linked loci and correlated allele frequencies. Genetics 164:1567-1587.
Felsenstein, J. 1985. Confidence limits on phylogenies: A justification. Evolution 39:783-791.

Hampson, M. C. 1993. History, biology, and control of potato wart disease in Canada. Can. J. Plant Pathol. 15:223-244.

Hampson, M. C., Yang, A. F., and Bal, A. K. 1994. Ultrastructure of Synchytrium endobioticum resting spores and enhancement of germination using snails. Mycologia 86:733-740.

Kamvar, Z. N., Tabima, J. F., and Grünwald, N. J. 2014. Poppr: An R package for genetic analysis of populations with clonal, partially clonal, and/or sexual reproduction. PeerJ 2:e281.

Karaoglu, H., Lee, C. M. Y., and Meyer, W. 2005. Survey of simple sequence repeats in completed fungal genomes. Mol. Biol. Evol. 22:639-649.

Langerfeld, E., and Stachewicz, H. 1994. Assessment of varietal reactions to potato wart (Synchytrium endobioticum) in Germany. EPPO Bull. 24:793-798.

Langerfeld, E., Stachewicz, H., and Rintelen, J. 1994. Pathotypes of Synchytrium endobioticum in Germany. EPPO Bull. 24:799-804.

Li, Y.-C., Korol, A. B., Fahima, T., Beiles, A., and Nevo, E. 2002. Microsatellites: Genomic distribution, putative functions and mutational mechanisms: A review. Mol. Ecol. 11:2453-2465.

Nei, M. 1978. Estimation of average heterozygosity and genetic distance from a small number of individuals. Genetics 89:583-590.

Niepold, F., and Stachewicz, H. 2004. PCR-detection of Synchytrium endobioticum (Schilb.) Perc. J. Plant Dis. Prot. 111:313-321.

Obidiegwu, J. E., Flath, K., and Gebhardt, C. 2014. Managing potato wart: A review of present research status and future perspective. Theor. Appl. Genet. 127:763-780.

Pritchard, J. K., Stephens, M., and Donnelly, P. 2000. Inference of population structure using multilocus genotype data. Genetics 155:945-959.

Rozen, S., and Skaletsky, H. 2000. Primer3 on the WWW for general users and for biologist programmers. Methods Mol. Biol. 132:365-386.

Sacristán, S., and García-Arenal, F. 2008. The evolution of virulence and pathogenicity in plant pathogen populations. Mol. Plant Pathol. 9:369-384.

Schuelke, M. 2000. An economic method for the fluorescent labeling of PCR fragments. Nat. Biotechnol. 18:233-234.

Shimizu, M., Kosaka, N., Shimada, T., Nagahata, T., Iwasaki, H., Nagai, H., Shiba, T., and Emi, M. 2002. Universal fluorescent labeling (UFL) method for automated microsatellite analysis. DNA Res. 9:173-178.

Simpson, E. H. 1949. Measurements of diversity. Nature 163:688.

Smith, D. S., Rocheleau, H., Chapados, J. T., Abbott, C., Ribero, S., Redhead, S. A., Lévesque, C. A., and De Boer, S. H. 2014. Phylogeny of the genus Synchytrium and the development of TaqMan PCR assay for sensitive detection of Synchytrium endobioticum in soil. Phytopathology 104:422-432.

Smith, I. M., McNamara, D. G., Scott, P. R., Holderness, M., and Burger, B. 1997. Quarantine Pests for Europe. Data Sheets on Quarantine Pests for European Union and for the European and Mediterranean Plant Protection Organisation, 2nd ed. CAB International, Wallingford, UK.

Tautz, D. 1989. Hypervariabflity of simple sequences as a general source for polymorphic DNA markers. Nucleic Acids Res. 17:6463-6471.

van den Boogert, P., van Gent-Pelzer, M., Bonants, P., De Boer, S., Wander, J., Lévesque, C., Van Leeuwen, G., and Baayen, R. 2005. Development of PCR-based detection methods for the quarantine phytopathogen Synchytrium endobioticum, causal agent of potato wart disease. Eur. J. Plant Pathol. 113:47-57.

van Gent-Pelzer, M. P., Krijger, M., and Bonants, P. J. 2010. Improved realtime PCR assay for detection of the quarantine potato pathogen, Synchytrium endobioticum, in zonal centrifuge extracts from soil and in plants. Eur. J. Plant Pathol. 126:129-133. 